\title{
Diagnóstico da qualidade em uma IES: a percepção da comunidade acadêmica
}

\author{
Sidnei Vieira Marinho \\ Gabriella Depiné Poffo
}

Resumo: Este artigo apresenta como objeto de estudo a percepção da qualidade em uma Instituição de Ensino Superior - IES, tendo como sujeitos da pesquisa os discentes, docente e o gestor. A pesquisa apresenta a análise descritiva de dados quali-quantitativos, acerca da percepção sobre qualidade educacional da comunidade acadêmica, observada à luz dos indicadores do Ministério da Educação. Os instrumentos de pesquisa aplicados para diagnosticar essa relação foram o questionário do Modelo HedPERF Adaptado aos discentes, entrevista ao corpo docente e entrevista ao gestor da IES. Os dados obtidos por levantamento estatístico foram triangulados em relação aos indicadores de qualidade apresentados pelo MEC em sua avaliação externa da IES em questão, a Faculdade AVANTIS. Como objetivo da pesquisa intencionou-se indicar uma perspectiva conceitual da qualidade educacional, desde os aportes teóricos aos instrumentos de avaliação disponíveis, que permitam orientar o gerenciamento nas IESs com vistas a atingir a qualidade educacional efetivamente. O principal resultado a se considerar concentrou-se em observar que a avaliação gerada pelos indicadores do MEC mostra um resultado inferior em relação à percepção dos sujeitos desta pesquisa, diante da aplicação do instrumento HedPERF Adaptado.

Palavras-chave: Qualidade. Ensino superior. Modelo HedPERF adaptado

Quality of Diagnosis in a Higher Education Institution: the perception of the academic community

Abstract: The purpose of this article is to present the quality perception in a higher education institution, by having as its research subjects the students, professors and managers. Thus, this research was developed by descriptive analysis of quantitative and qualitative datas, which its problematic was to present the perception about the educational quality in the academic community, regarding to indicators of the Ministry of the Education - MEC. The instruments applied in this research in order to identify this relation were the model HedPERF questionnaire, customized to the students, professors and managers interview. the datas acquired by statistical survey were connected related by quality indicators introduced by MEC in its external evaluation, which purposes in presenting important counterpoints or improvement to the educational management of the HEI, Faculdade AVANTIS. As the research purpose, it was intended to indicate a conceptual perspective of the educational quality, from the theoretical contribution to the evaluation instruments available, which allows to guide the management in the HEI. The main result to ponder is focused in checking the evaluation created by the MEC indicators, which presents a lower result, in relation to the subject perception of this research, before the employment of the instrument HedPERF Adapted.

Key words: Quality. Higher education. Model HedPERF adapted. 


\section{Introdução}

A presente pesquisa justifica-se pela necessidade de aprofundar estudos relacionados com a melhoria da qualidade educacional das IESs. De acordo, com Archer (1997) o Ensino Superior (ES), através de suas instituições, assume uma posição estratégica como eixo central de desenvolvimento qualitativo e produtivo da sociedade.

A qualidade educacional das IESs assume sua auto-representação, que exprime qualidade além de um conceito intrínseco e máster, pois torna-se um mecanismo de diferenciação, competição e sobrevivência da instituição. Portanto, estudar a qualidade educacional é tema relevante e tarefa complexa, em função dos inúmeros fatores que a compõe (TUTIKIAN; HOLZ, 2000). Para os autores Cheng e Tam (1997), a qualidade na educação é um conceito multidimensional e não pode ser avaliada por um único indicador, já que o grande fator está diretamente ligado com a perspectiva de quem recebe o serviço, ou seja, se há realmente qualidade nos serviços prestados pela IES.

O conceito de qualidade, em sentido amplo, descreve uma característica particular de um empreendimento: produção de bens ou serviços. Neste enfoque, a expectativa da qualidade no segmento da educação é mensuravelmente maior do que em qualquer outro, uma vez que as instituições de ensino possuem por responsabilidade a formação integral do ser humano, sem descuidar de sua formação profissional. Assim, no que tange as instituições de ensino superior Finger (2000) afirma que estas tem merecido estudos específicos por parte de pesquisadores, quer seja pelo papel social que desempenham ou pelas características peculiares que apresentam.

No Brasil, o Ministério de Educação (MEC) é responsável pela formulação de diretrizes e políticas com vista à qualidade educacional. Para Walter, Tontini e Domingues (2005) com a grande abertura de IES proporcionada pela Lei de Diretrizes e Bases da Educação Nacional (LDB) de 1996 (BRASIL, 2011b), o mercado educacional tornou-se competitivo. Porém, de acordo com Dias Sobrinho (2008) há uma importante e pertinente literatura que apresenta contrapontos aos processos avaliativos adotados pelo MEC que merecem atenção, constituindo-se objeto de análise desta pesquisa, dentre outros estudos igualmente relevantes para o monitoramento dos serviços educacionais das IES (OLIVEIRA-BROCHADO; MARQUES, 2007). Dentre estes, os instrumentos de avaliação dos cursos utilizados por este órgão, aplicados à Instituição de Ensino desta pesquisa que aqui se apresenta.

Neste sentido, define-se os contextos e sujeitos para pesquisar a qualidade da IES. E a partir destes, identifica-se os mecanismos e instrumentos metodo- 
lógicos adequados para conhecer as percepções dos sujeitos pesquisados para, por conseguinte, caracterizar e mensurar a qualidade por meio do levantamento destes dados.

Assim, defende-se a necessidade e relevância deste estudo, frente ao franco desenvolvimento do Ensino Superior, no Brasil. Seu crescimento, quantitativo e qualitativo teve um aumento vertiginoso focado na demanda, resultando um número aproximado de três mil Instituições, com trinta mil cursos e seiscentas mil vagas em cursos superiores (E-MEC, 2012). Frente a este crescimento, o governo federal criou o Sistema Nacional de Avaliação da Educação Superior - SINAES (BRASIL, 2012), que tem como finalidade buscar a melhoria da qualidade da educação, a qualificação da gestão, aumento da eficácia institucional e a efetividade acadêmica e social. Além disso, particularmente nas instituições privadas de ensino, agrega-se à questão da qualidade educacional com vistas às expectativas e percepções de seus clientes, a necessidade de manterem-se competitivas, num mercado cada vez mais concorrido.

A este cenário, soma-se a legislação de ensino que normatiza as ações do Ministério da Educação diante das instituições de ensino, o MEC dá a conhecer os conceitos e critérios de qualidade, conforme Portaria 40, consolidada em dezembro de 2010. No entanto, de acordo com Garcia, Vianna e Suñé (2012) o sistema de avaliação da educação superior aproxima-se do colapso, apresentando inconsistências técnicas, de inadequação legal, de morosidade e de inviabilidade sob o aspecto logístico. Por esta razão a idealização deste estudo, na intenção de analisar a concepção da qualidade educacional dos serviços prestados em uma IES sob a perspectiva da comunidade acadêmica, para verificar se as avaliações dos órgãos governamentais resultam em um conceito de qualidade que representam de fato a qualidade. Afinal, a administração de uma Instituição de Ensino vai além do simples interesse em atingir os objetivos administrativos de uma organização pois trata da responsabilidade de atender a sociedade em um dos seus mais valiosos ideais: a formação do indivíduo.

Há que se mencionar ainda que os estudos e pesquisas sobre qualidade educacional aumentou significativamente (DIAS SOBRINHO, 2008; SGUISSARDI, 1997; CATANI; OLIVEIRA; DOURADO, 2004; DIAS; HORIGUELA; MARCHELLI, 2006; LEITE, 2000; PEIXOTO, 2009). Dessa maneira, torna-se importante identificar os fatores críticos da qualidade educacional em uma IES que colabora para a subjetividade do processo educacional, sendo que, os processos de melhoria, dependem diretamente da gestão da Instituição.

Toda a organização moderna preocupa-se com a qualidade de seus produtos e serviços, alicerçados na alta exigência da comunidade externa. Jager e 
Gbadamosi (2009) defendem que os estudantes ingressantes no ensino superior possuem expectativas quanto aos serviços prestados e, com isso, a perspectiva da avaliação dos alunos tornou-se um requisito fundamental para a avaliação da qualidade em Educação Superior. Justifica-se, portanto, esta pesquisa sobre a qualidade de serviços educacionais que focaliza a percepção dos discentes, docentes e dos gestores de uma Instituição de Ensino Superior. Nesta ótica o presente estudo visou responder ao questionamento: a percepção sobre qualidade educacional da comunidade acadêmica identifica-se com os indicadores de qualidade do Ministério da Educação?

Para responder a esta questão, apresenta-se inicialmente uma breve apresentação sobre os conceitos de qualidade e o modelo HedPerf proposto por Firdaus (2006), adaptado e aplicado nesta pesquisa.

\section{Conceito de qualidade em instituição de ensino superior}

Qualidade, em termos gerais, significa um atributo ou característica de uma ação ou empreendimento. A literatura sobre o tema é vasta, como apresentado na introdução e sobre a qual discorrer-se-á no presente artigo, pois se trata de assunto de interesse da sociedade em geral, como das organizações produtivas em particular. Apresenta-se aqui alguns aportes, a título de subsídios, para compreensão abrangente do significado e origem da qualidade, incluindo-se os principais personagens, pioneiros, no estudo da problemática da busca da melhoria da qualidade no contexto das organizações. A maior parte dos princípios relativos ao Gerenciamento da Qualidade é derivada de um pequeno grupo de estudiosos. Pode-se denominá-los como mestres, ou gurus do conhecimento que visam compreender e analisar o processo de implantação da Qualidade Total em organizações. Sendo assim, este item abordará os enfoques que mais contribuíram para sua implementação, como os trabalhos de Ishikawa (1986) Deming (1990), Juran (1974), Campos (1992), Feigenbaun (1991, Crosby (1979), Robbins (2000) e Mañas (2006) acerca da Qualidade Total.

De acordo com as inúmeras definições que autores revelam acerca da qualidade dentro de qualquer organização, o primeiro passo deve ser sua definição sobre o que é qualidade para si própria. Consequentemente, a empresa impulsiona-se para trilhar seu caminho. Diante disso, e por toda a dificuldade e complexidade de conceituação da qualidade é que este trabalho segue apresentando uma breve referência da história da qualidade, demonstrando sua importância para as organizações.

A história da qualidade pode ser refletida através dos primórdios da civilização, desde que chefes, reis e faraós governavam suas terras. Porém, a profunda mudança da qualidade e suas novas conceituações vieram com a revolução 
industrial no século XVIII na Inglaterra, e sua radical mudança dos processos de fabricação (FINGER, 2000).

A origem da palavra qualidade tem influenciado os autores modernos que, cada um a sua visão, estabeleceram conceitos de diferentes maneiras. Os principais seriam, conforme Quadro 1:

\section{Quadro 1 - Conceito de qualidade estudado por diversos autores modernos}

\begin{tabular}{|c|c|c|}
\hline Ano & Autor & Significado da palavra qualidade \\
\hline 1974 & J. M. Juran & $\begin{array}{l}\text { O nível de satisfação alcançado por um determinado produto no } \\
\text { atendimento aos objetivos do usuário, durante o seu uso, é chamado } \\
\text { de adequação ao uso. Este conceito de adequação ao uso, popular- } \\
\text { mente conhecido por alguns nomes, tal com qualidade, é um conceito } \\
\text { universal aplicável a qualquer tipo de bem ou serviço. }\end{array}$ \\
\hline 1979 & Philip Crosby & $\begin{array}{l}\text { Qualidade quer dizer conformidade com os requisitos. Qualidade é o } \\
\text { atendimento às especificações definidas para satisfazerem os usuários }\end{array}$ \\
\hline 1986 & Kaoru Ishikawa & $\begin{array}{l}\text { Qualidade é o desenvolvimento, projeto, produção e assistência de } \\
\text { um produto ou serviços que seja o mais econômico possível e o mais } \\
\text { útil possível, proporcionando satisfação ao usuário. }\end{array}$ \\
\hline 1990 & $\begin{array}{l}\text { William Ec } \\
\text { Deming }\end{array}$ & $\begin{array}{l}\text { Qualidade consiste na capacidade de satisfazer desejos do cliente e } \\
\text { melhoria contínua }\end{array}$ \\
\hline 1990 & Campos & $\begin{array}{l}\text { Produto de qualidade é aquele que atende perfeitamente de forma } \\
\text { acessível, seguro, confiável e no tempo certo as necessidades do } \\
\text { cliente. }\end{array}$ \\
\hline 1991 & $\begin{array}{l}\text { Armand } \\
\text { Feigenbaun }\end{array}$ & $\begin{array}{l}\text { Qualidade quer dizer o melhor para certas condições do cliente. Essas } \\
\text { são: o verdadeiro uso e o preço de venda do produto. Qualidade é a } \\
\text { composição total das características de marketing, engenharia, fabrica- } \\
\text { ção e manutenção de um produto ou serviço, através das quais o mes- } \\
\text { mo produto ou serviço, em uso, atenderas expectativas do cliente. }\end{array}$ \\
\hline 1991 & Tebou & $\begin{array}{l}\text { Qualidade é a capacidade de satisfazer as necessidades tanto na } \\
\text { hora da compra, quanto durante a utilização, ao menos custo possível, } \\
\text { minimizando as perdas, e melhor que os nossos concorrentes. }\end{array}$ \\
\hline 1992 & Scholtes & $\begin{array}{l}\text { Qualidade é melhorar o processo de produção, aprendendo como ele } \\
\text { funciona, a fim de atender e fazer de forma confiável e independente } \\
\text { o que o cliente deseja. }\end{array}$ \\
\hline 1994 & Paladini & $\begin{array}{l}\text { Qualidade corretamente definida é aquela que prioriza o consumidor. } \\
\text { Isto mostra que a qualidade é mais do que simples estratégias ou } \\
\text { técnicas é, antes, uma questão de decisão que reflete em políticas } \\
\text { de funcionamento da organização. }\end{array}$ \\
\hline 1996 & Prazeres & $\begin{array}{l}\text { A qualidade é a totalidade de requisitos e características de um } \\
\text { produto ou serviço que estabelece a sua capacidade de satisfazer } \\
\text { determinadas necessidades. }\end{array}$ \\
\hline 2000 & Robbins & $\begin{array}{l}\text { Qualidade está estreitamente ligada ao critério de satisfação do cliente. } \\
\text { Ela abrange operações e processos internos, bem como avaliações } \\
\text { dos clientes. }\end{array}$ \\
\hline 2006 & Mañas & $\begin{array}{l}\text { O processo de qualidade na gestão e na prática existe como resultado } \\
\text { de um desafio maior que é a necessidade de manter-se atualizados. } \\
\text { As mudanças cada vez mais rápidas e globalizadas estabelecem } \\
\text { cobranças e os consumidores finais são cada vez mais exigentes. }\end{array}$ \\
\hline
\end{tabular}

Fonte: Elaborado pelos autores, 2012 
O quadro apresenta as perspectivas clássicas e consagradas pela Administração sobre o conceito de qualidade e os teóricos mais relevantes a respeito do seu estudo. Tanto que estes teóricos continuam desenvolvendo estudos acerca da dimensão da qualidade. Pesquisas recentes acerca desse conceito como de Bertolin (2009), Jager e Gbadamasi (2009), Tang e Wu (2009), Aper (2010), Antunes, Polito e Resende (2010), Cardoso, Santiago e Sarrico (2010), Souza e Reinert (2010) Barbosa, Freire e Crisóstomo (2011), Maguad (2011), corroboram a mesma conceituação dada ao conceito de qualidade. Em comum identificam as especificações da correlação entre a oferta-satisfação que estimula qualquer organização de prestação de serviço a oferecer produtos com a qualidade desejada pelo público alvo de cada atividade em relação ao mercado. As IESs particulares por sua vez, sendo empresas prestadoras de serviços educacionais, são inicialmente impulsionadas para o benefício no aprimoramento contínuo entre curso-docente-funcionário, ampliando a pesquisa em relação à qualidade para o aperfeiçoamento do próprio ensino.

No Brasil, a problemática da qualidade aplicada às IESs é tema altamente relevante em todas as dimensões da sociedade e, portanto, preocupação prioritária no âmbito educacional do Estado (BRASIL, 2012), cujos órgãos competentes, tais como SINAES, CONAES e outros são responsáveis pela implementação e regulamentação do ensino bem como da avaliação da QE.

Assim sendo, à luz dos subsídios acima apresentados, pode-se afirmar que não fácil a pesquisa em QE. Na realidade, à luz do contexto social, político, econômico e cultural em que se insere o ensino superior no Brasil, pode-se perceber as grandes pressões que as instituições de ensino suportam, tais como: evasão, desperdícios, inadequação dos currículos, inadimplências, desmotivação da gestão e do corpo docente, exigências tecnológicas, financiamento, concorrência, entre outros. Esses elementos podem ser apontados como os principais problemas que atingem o sistema de educação superior no país. São pressões internas e externas, que apesar do interesse do MEC e de seus órgãos competentes em estimular e criar indicadores específicos para a melhoria da QE, impedem a formulação de um modelo ideal e efetivo de análise da QE das IESs brasileiras (DIAS SOBRINHO, 1996; 2008)

Reconhecidamente, não existe um padrão ou um modelo único para se avaliar a qualidade em qualquer instituição de ensino. A QEs vem sendo discutida e aperfeiçoada pelo MEC através de definições e implementações de modelos de avaliação do ensino superior. Contudo, assim como no mundo empresarial 
a busca da melhoria da qualidade constitui-se numa preocupação dinâmica e contínua, a problemática da $\mathrm{QE}$ também se reveste dessa dinamicidade. Em função disso, têm sido criados, ao longo do tempo, vários modelos, estudos e experiências para avaliar a qualidade no âmbito educacional (ABMES, 2011)

No Brasil a preocupação com a qualidade das IESs iniciou-se a partir de 1995 com a implantação do conjunto de políticas setoriais de ES. Passam, desde então, a necessitar de um aparato legal para dar sustentação e avaliação eficaz ao acompanhamento pelo MEC da expansão quantitativa das IESs e diversificação do sistema do ensino superior brasileiro (DIAS SOBRINHO, 2010).

Diante deste cenário, pode-se perceber um entendimento geral de que os modelos que avaliam a QE, mesmo sem unanimidade conceitual, são fundamentais como ferramenta de gestão e, por esta razão devem ser estimulados, isto é, elaborados e experienciados em estudos práticos e em pesquisas acadêmicas. É prudente que as instituições, além de basearem-se nas dimensões e indicadores implantados pelo governo como forma de avaliação, formulem seus próprios modelos de avaliação da qualidade, de acordo com suas características e perspectivas.

O próximo item trata do modelo HEdPERF, criado por Firdaus (2006), onde afirma que os serviços de qualidade são concomitantemente uma atitude e julgamento em relação ao serviço prestado sendo um conceito de difícil contabilização visto a perspectiva subjetiva presente no juízo prestado pelo próprio consumidor.

\section{Modelo de qualidade}

Devido ao aumento expressivo de IES nos últimos anos, Firdaus (id.) sugere um novo modelo para avaliar a qualidade, denominado HEdPERF. Segundo Sousa et al. (2011), este modelo foi desenvolvido através dos instrumentos de estudos, SERVQUAL e SERVPERF. Seu objetivo está relacionado com apresentação e validação de uma nova escala de medição de qualidade dos serviços, especificamente para o ensino superior, utilizando técnicas quantitativas e qualitativas de medição.

De acordo, com a necessidade de análise dos modelos de aplicação para avaliação da qualidade dos serviços, o Quadro 2 a seguir, de forma resumida apresenta os modelos com seus respectivos pontos fracos e pontos fortes: 


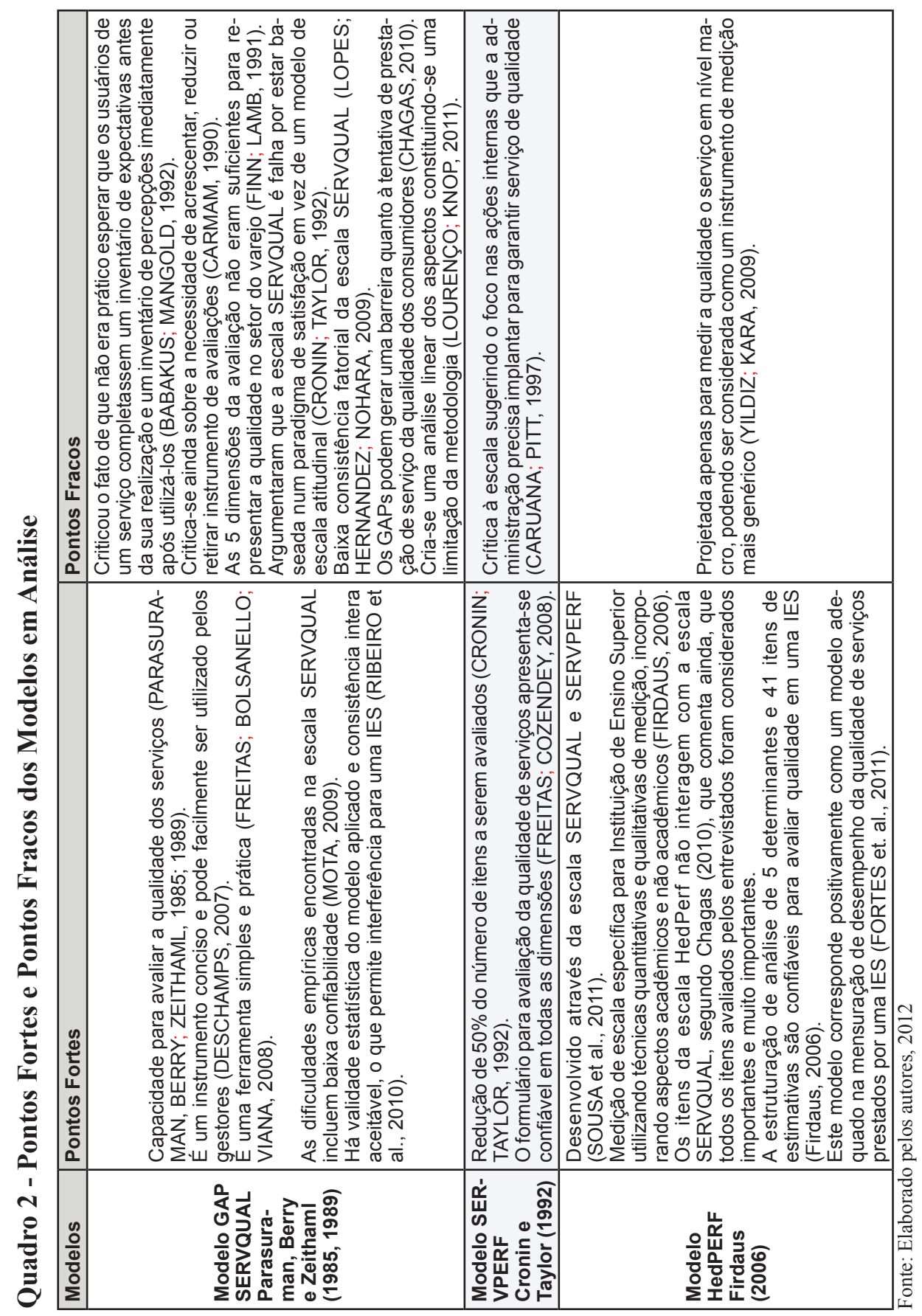


Para os autores Salomi, Miguel e Abackerli (2005) existe a validade de utilização das escalas SERVPERF e SERVQUAL para a medida da qualidade do serviço de manutenção, não havendo restrições quanto aos estimadores de confiabilidade e viabilidade da mesma ordem de grandeza quando aplicados para avaliação de qualidade de serviços externos.

Cada um desses modelos sugere dimensões ou atributos diferentes de análise, sendo que até o momento a sistematização desses modelos foi pouco estudada. Ladhari (2008) identificou e discutiu as principais questões que devem ser consideradas no desenvolvimento de uma escala específica para avaliação da qualidade de serviços, porém no sentido de amparar a avaliação de serviços prestados por instituições que ainda é incipiente.

Sousa et al. (2011) afirma que dentre os modelos de qualidade de serviços em estabelecimento de ensino superior, o estudo de Firdaus (2006) revelou que a medição da qualidade dos serviços, por meio do método HedPERF resultou em estimativas mais confiáveis, com maior critério de validade do construto, maior variância explicada e aparentemente superior ao modelo SERVPERF e SERVQUAL.

Os resultados de Brochado (2009) são semelhantes às analises de Firdaus (2006) confirmando a superioridade do modelo HEdPERF, no que tange a confiabilidade como um dos instrumentos de análise da qualidade de serviço no ensino superior. Portanto, tendo em vista que a literatura ainda carece de modelos alternativos para avaliar a qualidade educacional, particularmente, a qualidade de serviços prestados por uma IES. Pode-se afirmar que o Modelo HEdPERF, em conformidade com a validação proposta por Firdaus (2006), pode ser base para nortear estudos e amparar gestores e pesquisadores na busca da qualidade.

Os resultados por ele encontrados confirmaram que há cinco dimensões, ou seja, aspectos determinantes envolvidos na problemática da qualidade de serviço. São eles: a) aspectos não-acadêmicos; b) aspectos acadêmicos; c) reputação; d) acesso; e) conteúdos programáticos.

Neste contexto, um instrumento adequado de avaliação do ensino superior deve também estar direcionado a identificação das falhas da instituição em perceber as reais necessidades de seus alunos, o que contribui para fortalecimento da avaliação, evitando a ênfase em aspectos secundários do processo educacional (MOTA, 2009). Sendo assim, a utilização de um modelo de qualidade educacional pode contribuir para o entendimento da Instituição de acordo com a visão dos discentes referente aos critérios de qualidade da prestação de serviço, permitindo às IESs um direcionamento para as ações estratégicas e 
contínuas, em busca de uma gestão mais orientada para a qualidade do ensino e formação acadêmico-profissional.

Dando sequencia a este estudo, o próximo tópico refere-se à tipologia da metodologia aplicada, a delimitação da pesquisa, universo e amostra e por seguinte, a análise dos dados coletados.

\section{Metodologia da pesquisa}

Para atingir os objetivos a que este estudo se propôs, utilizou-se a tipologia, quanto à abordagem do problema, quali-quantitativa, visando à necessidade de analisar a percepção da comunidade acadêmica referente à qualidade de serviços educacionais oferecidos pela IES pesquisada. Há que se definir, então, o método da pesquisa realizada. Buscou-se o estudo de caso, por apresentar a "capacidade de lidar com uma variedade de evidências - documentos, artefatos, entrevistas e observações" (YIN, 2001, p. 27).

A pesquisa foi realizada na Instituição de Ensino Superior, Faculdade AVANTIS, localizada na Avenida Marginal Leste, 3.600, km 132, no bairro dos Estados do município de Balneário Camboriú - SC, durante o primeiro semestre letivo de 2012.

Os instrumentos de pesquisa foram aplicados, em forma de questionário, aos discentes dos oito Cursos de Graduação da Faculdade AVANTIS: Administração (linhas de formação em: Gestão de Pessoas, Comércio Exterior, Marketing e Micro, Pequena e Média Empresas), Ciências Contábeis, Sistemas de Informação (Informática), Psicologia, Direito, Educação Física (Licenciatura), Educação Física (Bacharelado) e Arquitetura e Urbanismo, além da entrevista ao corpo docente e ao gestor da IES, a fim de identificar a percepção destes referentes aos serviços prestados na IES.

Os dados foram levantados através da coleta de 313 questionários aplicados aos discentes da IES pesquisada, sendo subdivididos entre alunos ingressantes e concluintes, 74 entrevistas realizadas com os docentes e 1 entrevista realizada com o gestor. Ainda, por intermédio dos instrumentos de avaliação dos cursos realizados pelo MEC/INEP, com os resultados dos reconhecimentos e as autorizações dos demais cursos, documentos oficiais da Instituição.

Os dados foram analisados sob o aspecto da pesquisa quantitativa e qualitativa, utilizando-se para tanto do programa SPSS (Statistical Package for Social Sciences), que significa, em outras palavras, o tratamento estatístico para a obtenção de análise de dados em ciências sociais e aplicadas. Este programa favorece comparações entre dados cruzados, confiabilidade em sua mensuração, e de tomada de decisão em relação aos resultados obtidos (IBM SPSS STATISTICS, 2012). 
Afim de uma melhor interpretação dos dados quanti-qualitativos obtidos utilizar-se a de triangulação para o desenvolvimento da conjunção da análise dos dados. Esta modalidade de análise permite uma valorização progressiva dos dados, dando consistência a este trabalho. Pois, é a partir da triangulação desses dados que foi possível fazer inferências mais confiáveis e válidas a respeito da concepção de qualidade educacional.

Observe-se no quadro abaixo, abaixo, contendo a triangulação dos dados desta pesquisa, assim expressa:

\section{Quadro 3 - Triangulação da Pesquisa}

\begin{tabular}{|c|c|c|}
\hline MEC & $\begin{array}{c}\text { ENTREVISTA } \\
\text { (DOCENTE) }\end{array}$ & $\begin{array}{c}\text { MODELO HEDPERF ADAPTADO } \\
\text { (DISCENTE) }\end{array}$ \\
\hline Dimensão 1 & Perguntas 1 a 4 & Questões 22 a 33 \\
\hline Dimensão 2 & Perguntas 5 a 7 & Questões 01 a 09 e 20 a 21 \\
\hline Dimensão 3 & Perguntas 8 a 10 & Questões 10 a 19 \\
\hline Qualidade & $\begin{array}{c}\text { Pontos Fortes e Pontos Fracos } 34 \text { a } 41 \\
\text { (Pergunta 11) }\end{array}$ \\
\hline
\end{tabular}

Fonte: Elaborado pelos autores, 2012.

Portanto, pode-se notar que as 3 dimensões de avaliação de cursos do MEC foram desenvolvidas nos instrumentos técnicos de coleta de dados a fim de que a qualidade educacional da Faculdade AVANTIS, fosse discutida com propriedade.

O próximo tópico deste artigo apresenta de forma sucinta a análise do resultado da pesquisa. Os dados estatísticos foram tabulados e analisados, porém para este estudo, concentraram-se apenas análises descritivas, conforme segue.

\section{Análise dos resultados}

A pesquisa revelou, nas dimensões analisadas, perspectivas diferenciadas da qualidade indicadas pelo corpo discente e docente da IES pesquisada. Elegemos, para este artigo, alguns dos principais itens que são discrepantes aos resultados levantados a partir da aplicação do instrumento de avaliação da IES realizada pelo MEC/INEP, que permite a visualização parcial dos resultados encontrados nesta pesquisa. Dentre estes, a dimensão Reputação, que se refere à imagem profissional projetada pela IES. De um modo geral está relacionada ao ambiente interno e à percepção do ambiente externo, interferindo no relacionamento 
interpessoal entre discente e docente e todos os colaboradores da Instituição, apresentando a facilidade do diplomado empregar-se na profissão escolhida. Este item apresentou a maior rejeição entre os cursos, ou seja, têm-se aqui os menores indicadores de qualidade. Dentre os itens avaliados nesta dimensão que apresentou maior rejeição foi o item 11 referente à adequação dos instrumentos e equipamentos (computador, internet, etc.) na percepção dos discentes.

Ao verificar a entrevista dos docentes, também se percebe uma relação de insatisfação por parte dos mesmos, porém eles comentaram que há investimento por parte da Instituição nesse setor, um dos entrevistados comentou que "a Instituição tem feito forte investimento em equipamentos e material didático. Também cabe destacar a aproximação e apoio da Instituição com o professor, buscando sugestões e possibilitando-os sugerir, por exemplo, livros para enriquecer ainda mais nossa biblioteca".

Ao analisar a percepção dos docentes e discentes em relação ao conceito de qualidade do MEC a pesquisa mostra que há uma compatibilidade de dados nesse sentido. Abaixo, delineia-se o quadro por curso e suas dimensões avaliadas de modo geral, dando ênfase ao item com maior indicador de qualidade e o menor indicador de qualidade:

\section{Quadro 4 - dimensão geral dos cursos avaliados da faculdade AVANTIS}

\begin{tabular}{|l|l|l|}
\hline $\begin{array}{l}\text { Cursos de Graduação da } \\
\text { Faculdade AVANTIS }\end{array}$ & $\begin{array}{l}\text { Dimensão com Menor } \\
\text { Indicador da Qualidade }\end{array}$ & $\begin{array}{l}\text { Dimensão com Maior } \\
\text { Indicador da Qualidade }\end{array}$ \\
\hline Administração Ingressantes & Reputação & Conteúdo Programático \\
\hline Administração Concluintes & Reputação & Aspectos Não Acadêmicos \\
\hline Arquitetura e Urbanismo & Reputação & Aspectos Não Acadêmicos \\
\hline Contábeis Ingressantes & Reputação & Aspectos Acadêmicos \\
\hline Contábeis Concluintes & Aspectos Não Acadêmicos & Aspectos Acadêmicos \\
\hline Direito & Conteúdo Programático & Aspetos Não Acadêmicos \\
\hline Educação Física Licenciatura & Reputação & Aspectos Não Acadêmicos \\
\hline Educação Física Bacharelado & Reputação & Aspectos Acadêmicos \\
\hline Psicologia Ingressante & Reputação & Aspectos Acadêmicos \\
\hline Psicologia Concluintes & Acessibilidade & Aspectos Acadêmicos \\
\hline $\begin{array}{l}\text { Sistemas de Informação } \\
\text { Ingressantes }\end{array}$ & Reputação & Conteúdo Programático \\
\hline $\begin{array}{l}\text { Sistemas de Informação } \\
\text { Concluintes }\end{array}$ & Reputação & Aspectos Acadêmicos \\
\hline
\end{tabular}

Fonte: Elaborado pelos autores, 2012. 
Ressalva-se, como já comentado acerca da dimensão que apresentou o menor indicador de qualidade. Neste momento da continuidade das análises apresentar-se-á as dimensões com maior indicador de qualidade que foram os Aspectos Acadêmicos e Não Acadêmicos e Conteúdo Programático.

A dimensão Aspectos Acadêmicos são relacionados com a dimensão 2 do MEC. Apesar de alguns itens terem apresentado rejeição da hipótese, não apresentou resultados significativos. Para o MEC, em seu instrumento de avaliação, a dimensão 2 corresponde ao corpo docente, que se resume a sua titulação, carga horária, experiência do profissional, produção acadêmica, entre outros. Os relatórios apresentam a Instituição pesquisada com o "atende" revelando de forma significativa este aspecto da qualidade, sendo um dos itens mais bem avaliados pelo curso dentro da IES.

A outra dimensão que merece destaque refere-se aos Aspectos Não Acadêmicos que na pesquisa triangulada é apontada pela dimensão 1 do MEC. Esta dimensão trata da organização didático-pedagógica da instituição e apresentou pouca rejeição nos itens avaliados, conforme já mencionado em sua análise específica. No diagnóstico dos relatórios do MEC apresenta-se uma similaridade em relação à qualidade, onde em alguns apontamentos podem ser observados como sugestões de melhoria da qualidade. Dentro de um dos aspectos de avaliação do BRASIL (2011a) afirma-se que: "Quando as ações acadêmico-administrativas, em decorrência das auto-avaliações e das avaliações externas, no âmbito do curso, estão muito bem previstas e implementadas".

Dando explanação sobre os indicadores de qualidade, apresenta-se a seguir uma avaliação geral da IES referente aos resultados alcançados pelo Modelo HEdPERF Adaptado para a análise da percepção discente da qualidade:

\section{Gráfico 1 - Visão geral da qualidade discente da IES pesquisada}

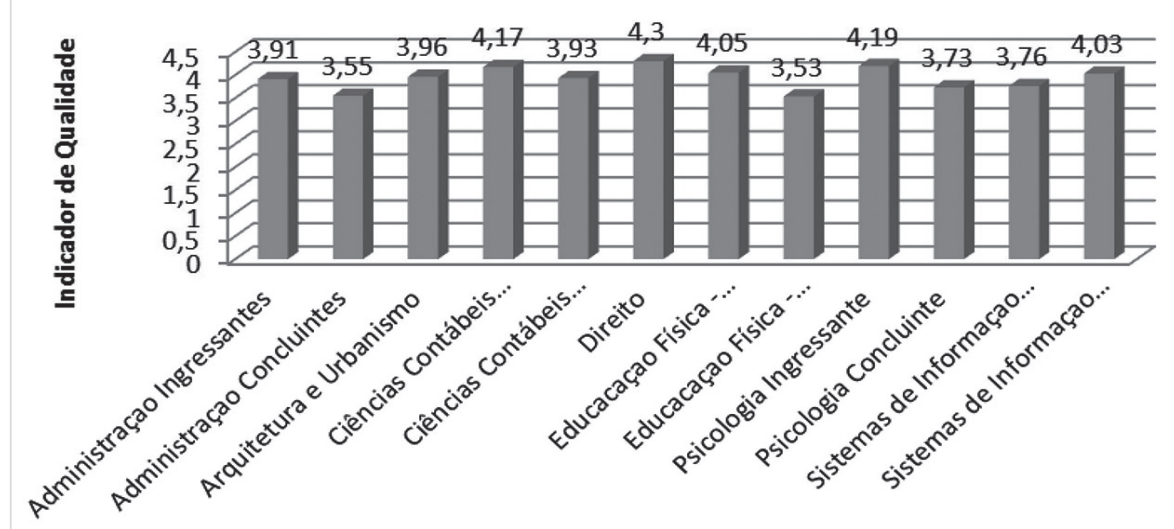


Em vista aos resultados apresentados pelo Modelo HEdPERF Adaptado, a seguir apresenta-se os conceitos atribuídos pelo MEC em sua avaliação aos cursos para neste momento identificar a qualidade dos mesmos respaldando a problematização apresentada.

\section{Gráfico 2 - Indicadores de Qualidade do MEC}

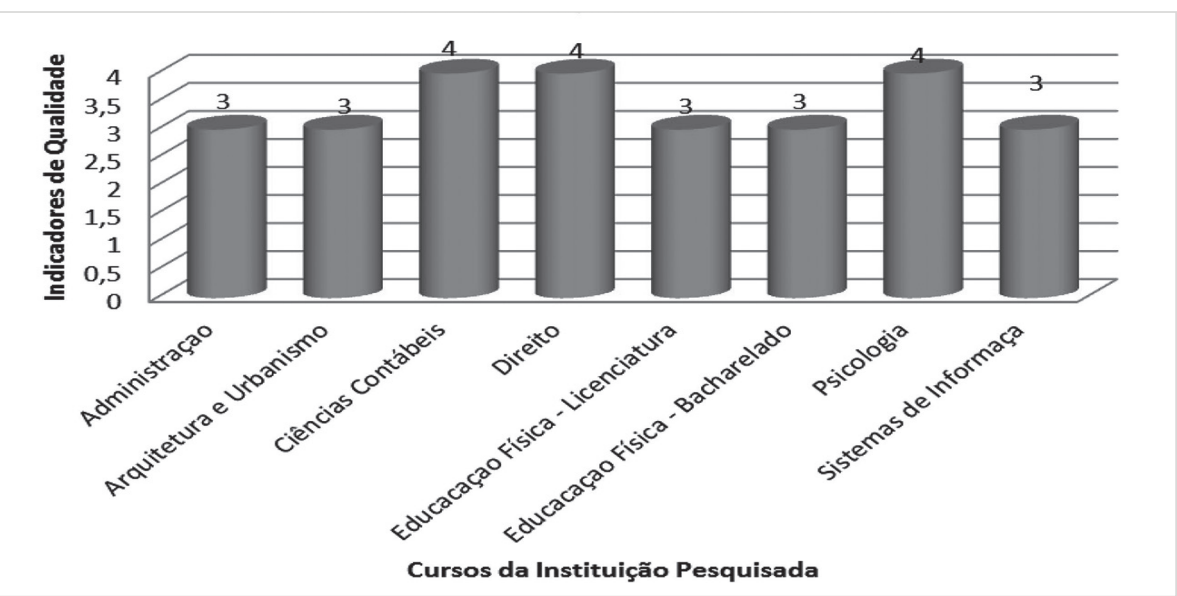

De uma maneira geral a qualidade da Instituição apresentada nos relatórios de avaliação, é perceptivelmente inferior às expectativas apresentadas pelos discentes ingressantes e/ou concluintes.

Vale ressaltar que a Instituição trabalha com o intuito de desenvolver o conceito 4 dentro das dimensões do MEC que em seu conceito descreve: "quando os indicadores da dimensão avaliada configuram um conceito Muito Bom/Muito Bem". Portanto, sendo esta a hipótese base para esta pesquisa.

Pelo fato da IES Faculdade AVANTIS enquadrar-se como "faculdade", de acordo com o decreto 5773/2006 em seu art. 27 tem-se a seguinte prerrogativa: "A oferta de cursos superiores em faculdade ou instituição equiparada, nos termos deste Decreto, depende de autorização do Ministério da Educação" (MEC, 2011a). Por isso, a Faculdade AVANTIS apresenta relatórios de avaliação externa que contém os conceitos de indicadores de qualidade proposto pelo MEC. Proporcionando, assim, mecanismos estratégicos como eixo do desenvolvimento da Instituição, onde a qualidade torna-se um mecanismo de diferenciação, competição e sobrevivência.

Outro fator de análise é de que a percepção dos alunos e o grau de satisfação não convergem para o atendimento da Instituição a fatores que são imper- 
ceptíveis para os discentes, como por exemplo, a acessibilidade, os Termos de Convênio e outros documentos que satisfazem aos instrumentos do MEC/ INEP. Nesta ótica, a percepção de qualidade possui foco de atenção e interesse distintos, mas que, como apresentado ao longo das análises dos dados desta pesquisa, são significativos na constituição do conceito de qualidade educacional em sua amplitude teórica-prática.

A fim de finalizar este estudo, apresenta-se abaixo as considerações finais, apresentando de forma sucinta e clara a percepção do autor de acordo com o diagnóstico da qualidade pesquisado na IES.

\section{Considerações finais}

No que concerne à qualidade, a literatura afere conceitos que delimitam a perspectiva deste tema como uma proposta estratégica de mudança, de crescimento e de aperfeiçoamento da organização como um todo para se atingir resultados melhores dentro da organização e de sua imagem no mercado.

Entende-se, neste sentido, que a qualidade é um instrumento e um mecanismo de excelência e persuasão no que tange a melhoria não somente dos serviços e produtos, mas também da oferta, procura e adequação da própria satisfação do consumidor.

Resumidamente, existem modelos para avaliar a qualidade dos serviços. Firdaus (2006) cria um modelo com a finalidade de criar uma estratégia para avaliar a qualidade de serviço especificamente em instituições na área do ensino superior. Para Firdaus (2006) é importante que as instituições possam fornecer serviços adequados em dimensões distintas podendo, desta maneira, verificar, quais delas merecem maior atenção para melhorar o crescimento institucional e garantir uma estabilidade de acordo com a influência da competitividade.

Em se tratando de Instituições de Ensino Superior, a qualidade assume um papel de grande importância através do cenário apresentado hoje no Brasil em que há um crescimento vertiginoso de Instituições, cursos e números de vagas oferecidas presenciais e a distância. Neste sentido, o INEP, mecanismo de avaliação do ensino superior brasileiro, está em constante formulação no que se refere aos indicadores de qualidade, buscando, assim, melhorias contínuas de um sistema de avaliação eficaz.

Neste cenário, a problemática dessa pesquisa foi justamente diagnosticar a percepção da qualidade da comunidade acadêmica - discentes, docentes e gestor - identificando com os indicadores de qualidade do MEC visando um diagnóstico da realidade da IES pesquisada, e para agregar novos conhecimen- 
tos nesta área foi utilizado o Modelo HerdPERF Adaptado sugerido inclusive por outros autores como Ladhari (2008), Brochado (2009), Chagas (2010) e Sousa (2011), como um modelo que confirma uma superioridade no que tange a confiabilidade das análises, com maior critério de validade do constructo, e maior variância explicada.

Todavia, não foi utilizado somente a perspectiva do Modelo HerdPERF Adaptado, mas em conjunto com a percepção da qualidade diagnosticada pelo MEC em avaliação in loco dos cursos da IES pesquisada. Além destes instrumentos, utilizou-se a entrevista aos docentes e a gestora da IES com a finalidade de corroborar os dados levantados através da pesquisa, permitindo a triangulação destes refletidos em uma pesquisa quali-quantitativa.

As análises permitem concluir que o curso que apresenta o melhor indicador de qualidade em todas as dimensões é o Curso de Direito. Já o curso que apresentou indicadores de qualidade inferior à hipótese dada pela pesquisadora, foi o curso de Educação Física Bacharelado.

As análises permitem concluir que os resultados coletados revelaram que os ingressantes de Administração e Psicologia percebem a qualidade relativamente superior do que os acadêmicos concluintes. Já no curso de Sistemas de Informação ingressantes percebem a qualidade inferior aos acadêmicos concluintes e para o curso de Ciências Contábeis não há discrepância entre ingressantes e concluintes na percepção da qualidade, dados estes que podem ser ponderados minuciosamente no corpo do trabalho.

Apesar do Modelo HerdPERF Adaptado se mostrar como um instrumento eficiente para a medição da qualidade educacional, ele apresenta alguns pontos fracos, que a princípio pode tornar a sua aplicação um tanto ousada e mal fundamentada. O presente comentário se faz pertinente uma vez que o Modelo HerdPERF elaborado por Firdaus (2006) é um instrumento muito recente e, em vista disso, ainda requer muitas pesquisas na área da educação superior a fim de constatar, como no caso desta pesquisa, a sua viabilidade e utilização práticas, embora não seja um instrumento muito flexível para adaptá-lo ao perfil do curso a ser estudado ou IES, sendo, portanto muito engessado em alguns parâmetros, dificultando, com isso, o apreço de algumas dimensões e conceitos. Todavia, sua aplicação se amplia em qualidade de informação quando desenvolvido e estruturado em conjunto com os indicadores do MEC, os quais desempenham um papel fundamental para a constatação e apuração da qualidade educacional brasileira. Mas do mesmo modo, em alguns pontos estes indicadores devem ser revistos levando em consideração o perfil institucional de cada curso como de cada IES. 
Conclui-se, portanto, que apesar das críticas em relação aos métodos de avaliação da qualidade pelo MEC, o mesmo, de certa maneira, apresenta uma congruência com as expectativas discentes, docentes e IES que contemplam os resultados desta pesquisa. Sugerem-se, nesse contexto, que há necessidades de outras pesquisadas em IES utilizando o Modelo HerdPERF Adaptado para a discussão da QE no ensino superior, com o objetivo de aperfeiçoar o Modelos de Avaliação da Qualidade em serviços, no que aumentará consecutivamente a confiabilidade nas investigações deste tema.

\section{Referências}

ABMES. Portaria Inep no 420, de 16 de novembro de 2011. Disponível em: <http://www.abmes.org.br/abmes/legislacoes/visualizar/id/1148>.

Acesso em: 16 nov. 2011.

ANTUNES, Marcelo Moreira; POLITO, Marcos Doederlein; RESENDE, Helder Guerra de. Aspectos interferentes na qualidade do curso de educação física na ótica do corpo discente. Avaliação, Campinas; Sorocaba, v. 15, n. 2, p. 163-182, jul. 2010.

APER, Jeff. P. Quality in higher education: systems and lifeworlds in collision. International Education, Tennessee, v. 40, n. 1, p. 55-67, 2010.

ARCHER, E. R. Mito da motivação. In: BERGAMINI, C. W. CODA, R. Psicodinâmica da vida organizacional: motivação e liderança. São Paulo: Atlas, 1997. p. 23-46.

BABAKUS, E.; MANGOLD, G. Adapting the Servqual scale to hospital services: an empirical investigation. Health Service Research, Chicago, v. 26, n. 2, p. 767-786, 1992.

BARBOSA, Glauber de Castro; FREIRE, Fátima de Souza; CRISÓSTOMO, Vicente Lima. Análise dos Indicadores de gestão das IFES e o desempeno discente no ENADE. Avaliação, Campinas; Sorocaba, v. 16, n. 2, p. $317-$ 344, jul. 2011.

BERTOLIN, Júlio. C. G. Qualidade em educação superior: da diversidade de concepções a inexorável subjetividade conceitual. Avaliação, Campinas; Sorocaba, v. 14, n. 1, p. 127-149, mar. 2009.

BRASIL. Decreto $n^{0}$ 5.773, de 9 de maio de 2006. Dispõe sobre o exercício das funções de regulação, supervisão e avaliação de instituições de educação 
superior e cursos superiores de graduação e seqüenciais no sistema federal de ensino. Disponível em: <http://www.planalto.gov.br/ccivil_03/_ato20042006/2006/Decreto/D5773.htm>. Acesso em: 25 ago. 2011a.

Lei $n^{\circ}$ 9.394, de 20 de dezembro de 1996. Estabelece as diretrizes e bases da educação nacional. Disponível em: <http://www.planalto.gov.br/ ccivil_03/leis/L9394.htm>. Acesso em: 25 maio 2011b.

Lei 10.861 de 14 de abril de 2004. Institui o Sistema Nacional de Avaliação da Educação Superior - SINAES e dá outras providências. Disponível em: < https://www.planalto.gov.br/ccivil_03/_Ato20042006/2004/Lei/L10.861.htm>. Acesso em: 21 mar. 2012.

BROCHADO, Ana. Comparing alternative instruments to measure service quality in higher education. Quality Assurance in Education, United Kingdom, v. 17, n. 2, p. 174-190, 2009.

CAMPOS, V. F. Gerencia da qualidade total: estratégia para aumentar competitividade dampresa brasileira. Belo Horizonte: Fundação Christiano Ottoni, 1990.

CAMPOS, V. F. T. Q. C.: controle da qualidade total (no estilo Japonês). Belo Horizonte: Fundações Cristiano Ottoni, 1992.

CARDOSO, Sónia; SANTIAGO, Rui; SARRICO, Cláudia. As atitudes dos estudantes face à avaliação das instituições de ensino superior. Avaliação, Campinas; Sorocaba, v. 15, n. 3, p. 29-58, nov. 2010.

CARMAM, J. M. Consumer perceptions of service quality: an assessment of the ServQual dimensions. Journal of Retailing, London, v. 66, n. 1, p. 33-35, 1990.

CARUANA, A; PITT, L. INTQUAL-na internal measure of service quality and the link between service quality and business performance. European Journal of marketing, London, v. 31, n. 8, p. 604-616, 1997.

CATANI, Afrânio Mendes; OLIVEIRA, João Ferreira; DOURADO, Luiz Fernandes. As políticas de gestão e de avaliação acadêmica no contexto da reforma da educação superior. In: MACEDO, Deise; FÁVERO, Maria de Lourdes de Alburquerque (Orgs.). Universidade: políticas, avaliação e trabalho docente. São Paulo: Cortez, 2004.

CHAGAS, Leila Rodrigues. Mapeamento da percepção dos alunos de uma escola de idiomas: uma adaptação do modelo HEdPERF. Dissertação (Mestrado) - Universidade Federal Fluminense, Niterói, 2010. 
CHENG, Yng Cheong: TAM, Wai Ming. Multi-models of quality in education. Quality Assurance in Education, United Kingdom, v. 5, n. 1, p. 22-30, 1997.

CRONIN, J.; TAYLOR, S Measuring service quality: a reexamination and extension. Journal of Marketing, Chicago, v. 56, n. 3, p. 55-68, jul. 1992.

CROSBY, P. B. Quality is free: the art of making quality certain. New York: Mc Graw-Hill, 1979.

DEMING, W. E. Qualidade: a revolução da administração. Rio de Janeiro: Saraiva, 1990.

DESCHAMPS, Marcelo. Avaliação de Qualidade no Ensino Superior: Aplicação dos modelos HEdPerf e SERVPERF na Faculdade de Tecnologia do SENAI/SC - Blumenau. Dissertação (Mestrado em Administração) - Centro de Ciências Sociais Aplicadas, Universidade Regional de Blumenau, Blumenau, 2007.

DIAS, Carmem Lúcia; HORIGUELA, Maria de Lourdes Morales; MARCHELLI, Paulo Sérgio. Políticas para avaliação da qualidade do ensino superior no Brasil: um balanço crítico. Educação \& Pesquisa, São Paulo, v. 32, n. 3, p. 435-464, set.-dez. 2006.

DIAS SOBRINHO, José. Avaliação institucional: Marcos teóricos e políticos. Avaliação, Campinas, v. 1, n. 1, p. 15-24, jul. 1996.

Avaliação educativa: produção de sentimentos com valor de formação. Avaliação, Campinas; Sorocaba, v. 13, n. 1, p. 193-207, 2008.

Avaliação e transformações da educação superior brasileira (1995 2009): do Provão ao SINAES. Avaliação, Campinas; Sorocaba, SP, v. 15, n. 1, p. 195-224, mar. 2010.

E-MEC. Instituição de Ensino Superior e Curso Cadastrado. Consulta Avançada. Disponível em: <http://www.emec.mec.gov.br.htm>. Acesso em: 20 maio 2012.

FEIGENBAUN, A. V. Total quality control. 3. ed. New York: Mc Graw Hill, 1991.

FINN, D. W.; LAMB, C. W. An evaluation of the Servqual scales in retail setting. Advances in Consumer Research, Minnesota, v. 18, p.483-490, 1991. 
FINGER, Andrew Beheregarai. A qualidade dos cursos de mestrado em Administração: uma avaliação pela percepção discente. Dissertação (Mestrado) - Universidade Federal de Santa Catarina, Florianópolis, 2000.

FIRDAUS, Abdullah. The development of HEdPERF: a new measuring instrument of service quality for the higher education sector. International Journal of Consumer Studies, Malden, v. 30, n. 6, p 569-581, nov. 2006.

FORTES, Victória Correa et al. Avaliação da qualidade no Ensino Superior: aplicação do modelo HedPerf em uma IES Privada. In: CONGRESSO NACIONAL DE EXCELÊNCIA EM GESTÃO, 7., Rio de Janeiro, 2011. Disponível em: <http://www.inovarse.org/filebrowser/download/8376>. Acesso em: 17 fev. 2012.

FREITAS, André Luis Policani; BOLSANELLO, Franz Marx Carvalho; VIANA, Nathália Ribeiro Nunes Gomes. Avaliação da qualidade de serviços de uma biblioteca universitária: um estudo de caso utilizando o modelo SERVQUAL. Scielo, Brasília, v. 37, n. 3, set-dez. 2008.

FREITAS, André Luis Policani; COZENDEY, Manaara Iack. Um modelo SERVPERF para avaliação de serviços hospitalares. In: ENCONTRO NACIONAL DE ENGENHARIA DE PRODUÇÃO, 28., Rio de Janeiro, 2008. Disponível em: <http://www.abepro.org.br/biblioteca/enegep2008_tn sto_070_502_10664.pdf $>$. Acesso em: 17 fev. 2012.

GARCIA, Maurício (Coord.); VIANNA, Nadja Maria Valverde; SUÑÉ, Letícia Soares de Vasconcelos Sampaio. Diagnósticos e propostas para a avaliação da educação superior no Brasil. Brasília: ABMES, 2012.

IBM SPSS Statistics. Disponível em: <http://www-01.ibm.com/software/ analytics/spss/products/statistics/>. Acesso em: 17 fev. 2012.

ISHIKAWA, K. TQC: Total Quality Control: estratégia e administração da qualidade. São Paulo: IM \& c Internacional Sistemas Educativos, 1986.

JAGER, Johan de; GBADAMOSI, Gbolahan. Specific remedy for specific problem: measuring service quality in South African higher education.

Higher Education, Amsterdam, v. 60, n. 3, p. 251- 267, summer 2009.

JURAN, J. M. Quality control handbook. 3. ed. New York. McGraw-Hill, 1974.

LADHARI, Riadh. Alternative measures of service quality: a review.

Managing Service Quality, United Kingdom, v. 18, p.65-86, 2008. 
LEITE, D. B. C. TUTIKIAN, Jane; HOLZ, Norberto. Avaliação e Compromisso: Construção e prática da avaliação institucional em uma universidade pública. Porto Alegre: Editora da UFRGS, 2000. p. 237. v. 1. LOURENÇO, Cléria Donizete da Silva; KNOP, Marcelo Ferreira Trezza. Ensino Superior em Administração e percepção da qualidade de serviços: uma aplicação da escala SERVQUAL. Revista Brasileira de Gestão de Negócios, São Paulo, v. 13, n. 39, p. 219-233, abr/jun/2011.

LOPES, Evandro Luiz; HERNANDEZ, José Mauro da Costa, NOHARA, Juliana Jordan. Escalas concorrentes para mensuração da qualidade percebida: Uma comparação entre a SERVQUAL e RSQ. RAE, São Paulo, v. 49, n.4, out/dez 2009

MAGUAD, Bem A. Deming's profound knowledge': implications for higher education. Education, A. L., v. 131, n. 4, p. 768-774, summ. 2011.

MAÑAS, Antonio Vico. Inovação e competitividade: um enfoque na qualidade. In: OLIVEIRA, Otáveio J. Gestão da qualidade: tópicos avançados. São Paulo: Pioneira Thomson Learning, 2006.

MOTA, Marilma Campos. Avaliação da qualidade do serviço educacional de uma IES particular: a visão do aluno de graduação sobre a qualidade percebida. Dissertação (Mestrado) - Universidade do Grande Rio, Professor José de Souza Herdy. Rio de Janeiro, 2009.

OLIVEIRA-BROCHADO, Ana; MARQUES, Rui Cunha. Comparing Alternative Instruments to Measure Service Quality in Higher Education. Research Work in Progress, Porto, n. 258, dez. 2007.

PARASURAMAN, A.; BERRY, Leonard L.; ZEITHAML, Valerie A. A conceptual model of service quality and its implications for future research. Journal of marketing, Chicago, p. 41-50, 1985.

Delivering Quality Service: Balancing Customer Perceptions and Expectations. Orlando: Quality Assurance Institute, 1989.

PEIXOTO, Maria do Carmo de Lacerda. Avaliação institucional nas universidades federais e as comissões próprias de avaliação. Avaliação: Revista da Avaliação da Educação Superior, Campinas, Sorocaba, v.14, n. 1, p. 9-28, mar. 2009.

PRAZERES, P. M. Dicionário de termos da qualidade. São Paulo: Atlas, 1996. 
RIBEIRO, Vagner Cavalcanti et. al. A validação estatística da escala SERVQUAL em IES: uma análise fatorial confirmatória. In: SEMINÁRIOS EM ADMINISTRAÇÃO, 13., São Paulo, 2010. Disponível em: <http:// sistema.semead.com.br/13semead/resultado/trabalhosPDF/692.pdf $>$. Acesso em: 17 fev. 2012.

ROBBINS, S. P. Administração: Mudanças e perspectivas. São Paulo: Saraiva, 2000.

SALOMI, Gilberto Gabriel Eid, MIGUEL, Paulo August Cauchick, ABACKERLI, Alvaro José. SERVQUAL X SERVPERF: comparação entre instrumentos para avaliação da qualidade de serviços internos. Gestão e Produção, v. 12, n. 2, p. 279-293, mai-ago 2005.

SCHOLTES, P. R. Times da qualidade: como usar equipe para melhorar a qualidade. Rio de Janeiro: Qualimarty, 1992.

SGUISSARDI, Valdemar. (org.). Avaliação universitária em questão: reformas do Estado e da Educação Superior. Campinas: Autores Associados, 1997.

SOUSA, Tarcita et al. Comparação de Modelos de Qualidade de Serviços: proposição estratégica para as Instituições de Ensino Superior. In:

SEMINÁRIOS DE ADMINISTRAÇÃO, 14., São Paulo, 2011. Disponível em: <http:/home.furb.br/mariadomingues/site/publicacoes/2011/eventos/ evento-2011-01.PDF> . Acesso em: 17 fev. 2012.

SOUZA, Saulo Aparecido de; REINERT, José Nilson. Avaliação de um curso de ensino superior através da satisfação/insatisfação discente. Avaliação, Campinas; Sorocaba, v. 15, n. 1, p. 159-176, mar. 2010.

TANG, Chia-Wei; WU, Cheng-Ta. Obtaining a picture of undergraduate education quality: a voice form inside the university. High Education, Netherlands, v. 60, p. 269-286, dec. 2009.

TEBOU, J. Gerenciando a dinâmica da qualidade. Rio de Janeiro: [S. 1.], 1991.

TUTIKIAN, Jane; HOLZ, Norberto . Avaliação e compromisso: construção e prática da avaliação institucional em uma universidade pública. Porto Alegre: Ed.UFRGS, 2000.

WALTER, S. A.; TONTINI, G.; DOMINGUES, M. J. C. S. Identificando oportunidades de melhoria em um curso superior através da análise da 
satisfação dos alunos. In: ENCONTRO NACIONAL DOS PROGRAMAS DE PÓS-GRADUAÇAO EM ADMINISTRAÇAO, 29. 2005, Brasília. Anais... Rio de Janeiro: ANPAD, 2005. 1 CD-ROM.

YILDIZ, S. M.; KARA, A. The pesperf scale: an instrument for measuring service quality in the school or physical educational and sports sciences (PEES). Quality Assurance in Educational, United Kingdom, v. 17, n. 4, p. $393-415,2009$.

YIN, Robert K. Estudo de caso: planejamento e método. 2. ed. Porto Alegre: Bookman, 2001.

Sidnei Vieira Marinho - Universidade do Vale do Itajaí Itajaí | SC | Brasil. Contato: sidnei@univali.br

Gabriella Depiné Poffo - Faculdade Avantis Itapema | SC | Brasil. Contato: pesquisadora@avantis.edu.br

Artigo recebido em 3 de abril de 2013 e aprovado em 23 de julho de 2013. 
